\title{
Future directions and management of liquid biopsy in non-small cell lung cancer
}

\author{
Alessia Maria Cossu ${ }^{1,2+^{*}}$, Marianna Scrima ${ }^{1 \dagger}$, Angela Lombardi ${ }^{2}$, Anna Grimaldi ${ }^{2}$, Margherita Russo ${ }^{2}$, \\ Alessandro Ottaiano ${ }^{3}$, Michele Caraglia ${ }^{1,2}$, Marco Bocchetti ${ }^{1,2}{ }^{*}$ \\ ${ }^{1}$ Biogem Scarl, Institute of Genetic Research, Laboratory of Molecular and Precision Oncology, 83031 Ariano Irpino, Italy \\ ${ }^{2}$ Department of Precision Medicine, University of Campania "Luigi Vanvitelli”, 80138 Naples, Italy \\ ${ }^{3}$ Department of Abdominal Oncology, SSD-Innovative Therapies for Abdominal Cancers, Istituto Nazionale Tumori di Napoli, \\ IRCCS “G. Pascale”, Via M. Semmola, 80131 Naples, Italy
}

${ }^{\dagger}$ These authors contributed equally to this work.

*Correspondence: Marco Bocchetti, Biogem Scarl, Institute of Genetic Research, Laboratory of Molecular and Precision Oncology, 83031 Ariano Irpino, Italy; Department of Precision Medicine, University of Campania "Luigi Vanvitelli”, 80138 Naples, Italy. marco.bocchetti@unicampania.it; Alessia Maria Cossu, Biogem Scarl, Institute of Genetic Research, Laboratory of Molecular and Precision Oncology, 83031 Ariano Irpino, Italy; Department of Precision Medicine, University of Campania “Luigi Vanvitelli", 80138 Naples, Italy. alessiamaria.cossu@biogem.it

Academic Editor: Floriana Morgillo, Università degli studi della Campania, Italy

Received: May 19, 2020 Accepted: July 8, 2020 Published: August 31, 2020

Cite this article: Cossu AM, Scrima M, Lombardi A, Grimaldi A, Russo M, Ottaiano A, et al. Future directions and management of liquid biopsy in non-small cell lung cancer. Explor Target Antitumor Ther. 2020;1:239-52. https://doi.org/10.37349/ etat. 2020.00015

\begin{abstract}
Lung cancer represents the world's most common cause of cancer death. In recent years, we moved from a generic therapeutic strategy to a personalized approach, based on the molecular characterization of the tumor. In this view, liquid biopsy is becoming an important tool for assessing the progress or onset of lung disease. Liquid biopsy is a non-invasive procedure able to isolate circulating tumor cells, tumor educated platelets, exosomes and free circulating tumor DNA from body fluids. The characterization of these liquid biomarkers can help to choose the therapeutic strategy for each different case. In this review, the authors will analyze the main aspects of lung cancer and the applications currently in use focusing on the benefits associated with this approach for predicting the prognosis and monitoring the clinical conditions of lung cancer disease.
\end{abstract}

\section{Keywords}

Non-small cell lung cancer, biomarkers, liquid biopsy, circulating cell-free tumor DNA, molecular analysis

\section{Introduction}

Lung cancer is among the most diagnosed tumor in the world and it represents the major cause of demise. Over 1.2 million lung cancer deaths are registered [1]. Lung cancer is categorized in two main groups: small cell lung cancer (approximately 20\%) and non-small cell lung cancer (NSCLC, approximately 80\%) [2]. 
The 5-year survival rate of lung cancer patients is between $4 \%$ and $17 \%$, according to different stages and regions [3]. Cigarette smoking represents the main risk factor. However, the risk of carcinoma development can be hereditary and probably derives from the presence of a rare autosomal dominant gene frequent in the population [4]. The high mortality rate is often due to late diagnosis, given when the tumor is already at an advanced stage and most patients will not respond to therapy. Previous disclosures underlined a precious method for the screening of asymptomatic NSCLC patients in a potentially treatable stage, in order to improve the healing. Lung cancer diagnosis is made by radiography, sputum cytology, bronchoscopy, needle biopsy, and other techniques. Adjuvant chemotherapy combined with radiotherapy can produce a survival advantage compared to the adjuvant irradiation. In cases of advanced and extensive NSCLC combination chemotherapy is usually recommended, in particular with drugs such as paclitaxel, docetaxel, and gemcitabine, etc. Surgery has only a limited role in the management of NSCLC. The combination of platinum-based chemotherapy plus radiation therapy is required for patients with locally advanced disease [5]. Currently, mutations in the epidermal growth factor receptor $(E G F R)$ and translocations involving the anaplastic lymphoma kinase $(A L K)$ gene are among the most important targets for targeted therapy [6]. In addition, many mutations in the B-Raf proto-oncogene (BRAF), human epidermal growth factor receptor 2 (HER2), hepatocyte growth factor receptor coding gene (MET), phosphatidylinositol-4,5-bisphosphate 3-kinase catalytic subunit alpha (PIK3CA), ROS proto-oncogene 1 (ROS1), proto-oncogene tyrosine-protein kinase receptor coding gene ( $R E T$ ), protein kinase $\mathrm{B}(A K T)$, discoidin domainreceptor tyrosine kinase 2 (DDR2), and K-Ras protein coding gene $(K R A S)$ genes have a certain relevance for target therapy [7]. In recent years, several new strategies targeting EGFR mutations, ALK fusions, ROS1 fusions, BRAF V600E mutations, and neurotrophin receptor tyrosine kinase (NTRK) fusions are emerging [8]. Moreover, some immune checkpoint inhibitors such as $\mathrm{T}$ lymphocyte-associated cytotoxic protein 4 (CTLA-4) and programmed death-1 (PD-1) and its ligands (PD-L1 and PD-L2) have been proposed to escape the immune system surveillance, opening the way for the evolution of specific monoclonal antibodies [9]. The use of conventional chemotherapy, oncogene target agents, immune system, or $\mathrm{T}$ cell checkpoint inhibitors showed significantly higher efficacy against earlystage tumors. Therefore, some more specific and sensible diagnostic tests are intertwined with new therapies development: the more tumor detection in the early initial phase is efficient; the better is the response to the therapy. A valid approach in high-risk subjects is represented by low dose computed tomography (LDCT). LDCT helps in the early diagnosis of the tumor, together with the traditional tissue biopsy to confirm the characteristics of the nodule observed by the CT scan. In fact, this method detects more than twice the number of lung tumors at an early stage and has been associated with a significant reduction in specific mortality of lung cancer compared to chest X-ray [10]. Despite its high sensitivity, both the National Lung Screening Trial (NLST) and other European studies showed relatively low specificity, with a high false-positive rate [11]. In addition, the NSLT study found that LDTC reduced mortality slightly; this evidence has raised some doubts about the benefit of LDCT in high-risk populations $[12,13]$. The diagnosis of metastatic NSCLC is often based on small biopsies or on cytological samples that sometimes are not sufficiently suitable for optimal molecular analysis. Furthermore, tissue biopsy may not necessarily represent the global molecular panorama of the tumor because it is performed on a specific site of a non-heterogeneous tumor. In this light, the use of less invasive techniques has become essential, complementary with radiological approaches currently in use. A valid contribution for prognostic and diagnostic screening is represented by the evaluation of circulating biomarkers. Liquid biopsy compared to tissue biopsy certainly has the advantage of being a non-invasive evaluation technique of tumor-specific biomarkers present in body fluids [14]. In particular, liquid biopsy provides an in-depth knowledge of the genetic profile of cancer and metastases, improving survival times and promoting selective therapy that can increase or suppress cellular growth; on the contrary, tissue biopsy is less effective, because it can only provide limited tumor vision in a single time point [15]. In fact, the disadvantages of tissue biopsy led the oncology field to switch the focus on the evaluation of the circulating components in the bloodstream because they are more effective for monitoring the disease and following any newly acquired resistance to therapy. Liquid biopsy is able to isolate and analyze different components derived from the tumor and provide essential information to characterize its molecular profile and capture metastatic heterogeneity [16]. These components, isolated from the bloodstream, urine, cerebrospinal fluid, 
saliva and pleural effusions [17], are circulating tumor DNA (ctDNA), cell-free tumor RNA (ctRNA), exosomes, miRNA, tumor-educated platelets (TEPs), and circulating cancer cells (CTCs) (Figure 1).
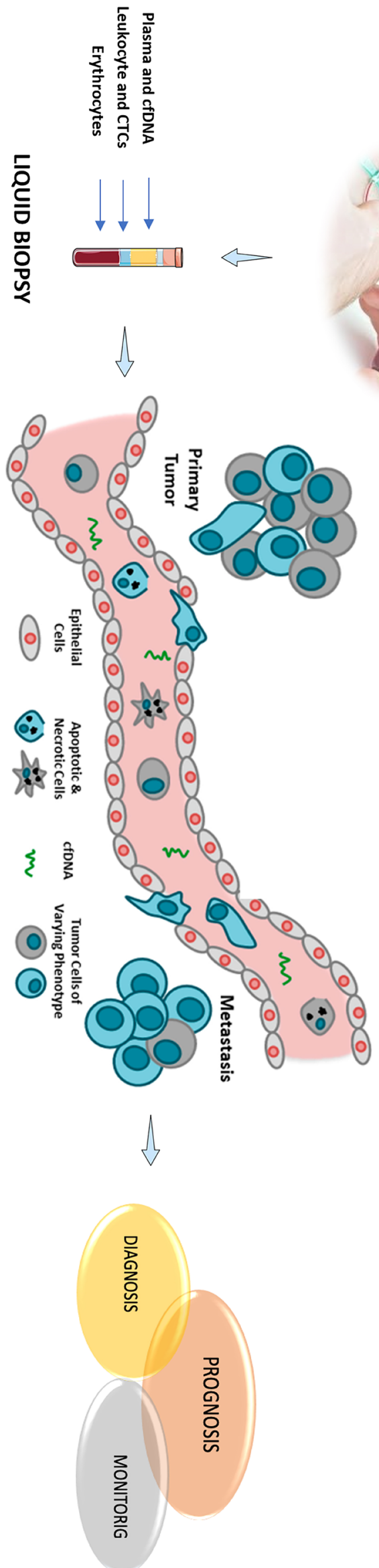

Figure 1. Overview of molecular liquid biopsy components. cfDNA: cell-free DNA 
Liquid biopsy can detect a considerable number of mutations, like point mutations, small insertions and deletions. However, this approach could detect other genetic aberrations such as the size of the DNA fragments, variations in the number of copies, translocations and epigenetic alterations. There are several highly sensitive digital systems for detecting circulating tumor DNA. These technologies such as polymerase chain reaction (PCR), real-time quantitative polymerase chain reaction (qPCR), the digital droplet-polymerase chain reaction (ddPCR), beads, emulsion, amplification and magnetics (BEAMing) are widely used in the cancer research field and only recently, next generation sequencing (NGS) has been shown to be a valid system in the evaluation of tumor specific alterations, allowing the sequencing of small amount of nucleic acids. Personalized medicine is now a crucial approach based on exploiting patients' genetic information to select or optimize the adjuvant therapy tied to the specific tumor and to individual's need. ctDNA analysis is essential since it enlightens about tumor heterogeneity and clonal evolution and provides a more complete molecular profile about changing subclone population and increase therapy efficacy. The important information on the gene changes during the disease obtained from the liquid biopsy increase the interest of this approach [18].

Therefore, it can be useful for early diagnosis of relapses before tumors become radiographically or clinically evident, offering to clinicians a wider window opportunity in which the treatment regimens could be modified [19]. Once a patient relapses, liquid biopsies can reveal new mutations not originally present in the primary tumor that could guide a choice for second-line therapy. The approaches identified in liquid biopsy are summarized here in order to point out the importance of these methods in diagnosing, prognosis and monitoring the treatment of disease.

\section{Aspects of circulating tumor biomarkers in liquid biopsies CTCs}

Recent studies have highlighted CTCs role as potential prognostic, diagnostic and monitoring biomarkers [20]. CTCs provide a real tumor snapshot (DNA, RNA and proteins) ready to be analyzed and they might prove useful to perform ex vivo functional studies and cultures, as well [16]. The isolation of CTCs occurs through methods presenting a great variability in detection rates, sensitivity and specificity. There is only one technique approved by the U.S. Food and Drug Administration (FDA) for CTCs isolation: CellSearch ${ }^{\mathrm{TM}}$ (Veridex LLC), i.e. magnetic microspheres with anti-epithelial cell adhesion molecule antibodies (EpCAM). This technique has been approved for metastatic breast, colorectal or prostate cancer [21, 22]. Isolation of CTCs is very demanding in NSCLC, compared to other cancers since it is a tumor with high aggressiveness and invasiveness. In fact, the isolation of CTCs in NSCLC is less effective. CTCs can be lost as they undergo to epithelial-mesenchymal transition (EMT) and for the down-regulate of their epithelial markers during progression. Therefore, the initial EMT does not have the ability to resize the epithelial properties of cancer cells and it is difficult to discriminate those markers with existing techniques [23]. Several techniques can be used in NSCLC metastatic tumors such as the "CTC-chip" characterized by the use of antibodies to isolate CTCs: a technique that successfully detects CTCs in the blood with $50 \%$ of purity [24]. Other techniques take advantage of intrinsic properties, such as size (e.g., ISET; Rare Cell Diagnostics, Paris, France), deformability, or dielectric sensitivity and/or negative selection of white blood cells $[25,26]$. Some mutations like EGFR, KRAS or the expression of MET have been detected in lung cancer. Their analysis becomes an additional method to complement the ctDNA test to facilitate monitoring of the patients response for a personalized therapy [27-30]. In a recent work, a technique called ISET was used to detect malignant circulating cells in patients with asymptomatic NSCLC [31]. However, several studies have enlightened the relevance of CTCs as prognostic and diagnostic sources of information. CTCs have been used as valid biomarkers to prevent lung tumors, as showed in chronic obstructive pulmonary disease [32]. Similarly, a study on early-stage NSCLC patients suggested that folate receptor positive CTCs could be used as diagnostic biomarkers [33]. However, despite the positive results regarding the value of CTCs as diagnostic biomarkers, there is no reliable evidence in the clinic in NSCLC [34]. In fact, new technologies to detect CTCs are now being developed (Figure 2). The methods currently in use are represented by erythrocyte lysis and cell centrifugation with long processing times and high costs. For these reasons, it is necessary to develop a system capable of limiting the loss of CTCs during isolation and increase the level of purity and establish a standard protocol to efficiently isolate 
vital CTCs suitable for in vitro expansion and ex vivo clinical applications [35]. A valid alternative to those systems is represented by nanotechnologies, with unique physical properties able to overcome the limits of traditional CTC detection methods [36].

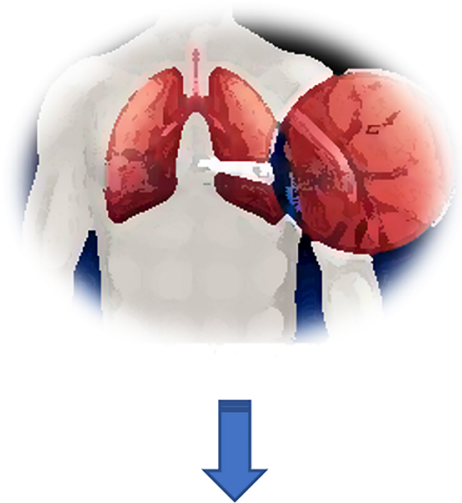

APPLICATION

\section{Immunostain}

\section{$\mathrm{FISH}$}

\section{CTCS DETECTION}

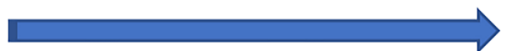

\section{Expression analysis}

\section{CTCs isolation}

\section{Cell culture}

Figure 2. Applications of CTC technologies

\section{cfDNA and ctDNA}

ctDNA is a fraction of cfDNA which differs from normal circulating DNA and it is characterized by specific mutations in oncogenes or suppressor genes $[14,16]$. Consequently, ctDNA is more concentrated in sick than in healthy subjects [37]. Cancer specific ctDNA provides molecular clues on the fragmented DNA of tumors and their specific mutations [35]. The ctDNA release mechanisms in the bloodstream are not yet clear, but it has been assumed that it can be released following apoptosis or cell lysis due to necrosis [38]. ctDNA is important because it can provide a picture of what are the mutations occurred to oncogenes or tumor suppressor genes, genetic amplification or epigenetic alterations of the patient [39]. Generally, ctDNA appears fragmented and mixed with non-tumor DNA at very low concentrations $(0.01-1 \%$ cfDNA), thus making it difficult to quantify it in the early stage of the disease.

It is possible to discriminate ctDNA from cfDNA through ultra-sensitive analytical assays. The methods currently in use to analyze the extracted cfDNA are PCR, digital PCR (dPCR), ddPCR, the clamp-based peptide acid-based PCR test, peptide nucleic acid (PNA) Taqman dosage, microspheres, BEAMing, polymerization managed by pyrophosphorolysis and new NGS [40]. The NGS technique advanced technology can detect multiple mutations present through a single test in a very short time [41]. Sozzi et al. [17], showed a sensitive and 
specific real-time qPCR test, efficient for plasma DNA evaluation; it represents a new non-invasive approach to identify individuals with lung cancer or with the risk to develop the disease. Gautschi et al. [42], demonstrated that the plasma and serum DNA concentration was higher in NSCLS subjects than in healthy subjects.

It is clear that the quantification of cfDNA could be exploited as an additional screening together with those currently in use including chest CT scans and cytological/histological examination, because it is more promising and effective in the prognosis and diagnosis of carcinoma. Currently, in addition to the NGS technique, Cancer Personal Profiling through deep Sequencing (CAPP-Seq) also represents a valid tool; it is an even more sensitive approach, capable of eliminating wild-type background DNA from normal cells and detecting multiple classes of somatic mutations. Therefore, it appears useful to monitor treatment response, residual disease and progression before radiological approaches [43]. Although cfDNA shows an important prognostic and diagnostic value, clinical application is still limited due to the lack of standardization.

\section{Exosomes and miRNAs}

Exosomes are extracellular vesicles measuring between 30-100 nm. Almost all cell subtypes are able to secrete those endocytosis generated vesicles, that's why it is possible to find them in different body fluids like pleural and cerebrospinal fluid, saliva, sperm and of course plasma and serum [44]. Exosomes contain different cellular product such as proteins, DNA, mRNAs, and miRNAs. Exosomes are crucial intermediaries between cells in a variety of diseases, including cancer, but also in physiological circumstances [45]. These vesicles are involved in tumor growth, progression, drug resistance and in the preparation of metastatic niche $[16,46]$. Different techniques are described to help with their isolation. It is possible to extract exosomes from the above-mentioned fluids by density centrifugation or ultracentrifugation, transmission microscopy, and protein markers exploitation (CD9, CD63, tetraspanin proteins). Extracellular vesicular matrix or immunobead precipitation $[16,47]$ are also described as isolation methods. Exosomes with tumor origin can contain oncogenic material, causing cancerous transformations in receiving cells. An example is the transfer of EGFR to vascular endothelial cells, together with their own vascular endothelial growth factor (VEGF) [48]. The extraction of miRNAs from biological fluids could give some information about somatic mutations, junction variants, or valuable knowledge on protein and gene expression using enzymelinked immunosorbent assay (ELISA) or Western Blot analysis together with NGS and real time polymerase chain reaction (RT-PCR) profiling. miRNAs contained inside exosomes are physically protected from RNAse degradation and their concentration in the bloodstream is generally higher. miRNAs are studied extensively due to their potential use diagnostic biomarkers in pulmonary adenocarcinoma [49]. Under this light, the most promising exosomal miRNAs are miR-21, miR-146, miR-17-3p, miR-210, miR-106a, miR-203, miR-214, miR-155, miR-212, miR-191, and miR-192. miR-23a, in particular, is involved in lung cancer progression by suppressing the development of propylhydroxylase, increasing the accumulation of hypoxia-inducible factor 1- $\alpha$, facilitating the transendothelial passage of malignant cells [50]. miR-151a-5p, miR-30a-3p, miR-100, miR-200b-5p, miR154 and miR-629 were also highlighted as diagnostic biomarkers important to discriminate pulmonary granuloma and adenocarcinoma [51]. A recent study using miRNA-seq showed a unique expression pattern shared between squamous cell carcinoma (SCC) and stage I adenocarcinoma patients. In particular, an exosomal prophylactic profile of tumor-derived miRNA was analyzed showing $80.65 \%$ and $83.33 \%$ sensitivity and $91.67 \%$ and $90.32 \%$ specificity for adenocarcinoma and SCC diagnosis, suggesting their potential role in NSCLC early diagnosis as non-invasive and high sensitive biomarker [52]. The exosomes in lung cancer serum patients also mediate EMT and metastasis in healthy cells by increasing vimentin expression [53]. Moreover, exosomes surface membrane proteins like CD317, CD91 and EGFR might represent potential tumor makers [54]. miRNAs are believed important in tumor profiling and crucial for early diagnosis, treatment response, and cancer recurrence marker and may predict the overall survival, as well.

\section{TEPs}

After red cells, platelets are the most abundant cells within the bloodstream. Platelets can be considered immune system "scanning soldiers", sensing the presence of bacteria, cross-communicating with lymphocytes, 
and partially regulating immune cell extravasation [55]. They have a significant role in several pathological processes like EMT, which increases the cancer cells ability to penetrate and invade distant tissues exploiting the circulation; they also create a neovascularization supportive environment by stimulating the expression of proangiogenic factor secretion such as platelet-derived growth factor (PDGF), VEGF, and basic fibroblast growth factor (bFGF) [56,57], inducing tumor cell apoptosis and anoikis and epithelial-mesenchymal switch in tumor cells by direct physical interaction and release of transforming growth factor beta (TGF $\beta$ ) molecules [58]. Platelets act protecting circulating tumor cells from the normal immune response, through several growth and proangiogenic factors release [59] significantly contributing to metastatization [60]. They are highly involved in tumor microenvironment and important factors in cancer biology as they contribute to tumorigenesis and progression, and to response to therapy. Moreover, platelets form a cell-fibrin-plateletaggregate surrounding CTCs providing mechanical protection [61]. TEPs can be considered non-invasive biomarkers suitable for RNAs panels determination. In fact, spliced TEP RNA surrogate signatures might give specific information about the presence, localization and cancer molecular phenotype. Platelets carry high amount of genetic material: RNAs, such as miRNAs, pre-mRNAs, mRNAs, circular RNAs (cirRNA), long noncoding RNAs, and mitochondrial DNA [62]. Certainly, platelet activation can induce subsequent pre-mRNA splicing and protein translation [63]. Platelets count and size give information about the putative tumor presence; in fact, a high count is associated to increased mortality in different tumors such as malignant mesothelioma, gynaecological malignancies and lung, kidney, gastric, colon cancers rectum and breast [64]. In NSCLC, tumor-derived platelet factor 4 [PF4, chemokine (C-X-C motif) ligand 4 (CXCL4)] [65] has been reported to promote megacarbonite-mediated platelet production in the bone marrow and an RNA panel was altered in TEPs in metastatic NSCLC patients [66]. Spliced RNA profiles are easily identifiable by minimal amounts of platelet RNA (100-500 picograms) through the thromboSeq platform, a methodology based on RNA sequencing. This allowed the metastatic carcinoma patients individuation with accuracy between $84 \%$ and $96 \%$ and identified surrogate signatures of spliced RNAs, associated with the molecular subtype of the tumor tissue, such as EGFR and KRAS mutations and HER2 and MET amplification [67]. An algorithm, called swarm-intelligence, has recently been implemented and iteratively optimizes the RNA panel to select a set of biomarkers [68]. This system allows the diagnosis of advanced stage NSCLC with an accuracy of 89\% in an independent validation cohort. Nilsson et al. [69], through RT-PCR noticed echinoderm microtubuleassociated protein-like 4 (EML4)-ALK rearrangements in platelets derived from NSCLC patients blood with $100 \%$ specificity and $65 \%$ sensitivity. $E M L 4-A L K+$ platelets patients had a remarkably lower progression-free survival: 3.8 months, compared with 16 months showed by patients with $E M L 4-A L K$ - platelets. Moreover, 30 months monitoring of EML4-ALK rearrangements in patients platelets revealed the occurrence of crizotinib resistance onset two months earlier than radiologic disease progression [69]. Sheng et al. [70], carried out a support vector machine network analysis on RNA-seq data derived from 402 NSCLC patient platelets, compared with 231 healthy donors. Target genes were 48, and several modules appeared to play crucial roles in this tumor onset and progression, like Wiskott-Aldrich Syndrome Protein Family Member 1 (WASF1), Arginine and Serine Rich Coiled-Coil 1 (RSRC1), Protein Kinase AMP-Activated Non-Catalytic Subunit Beta 2 (PRKAB2), Pyruvate Dehydrogenase E1 Subunit Beta (PDHB), Myosin Light Chain 9 (MYL9), Tropomyosin 2 (TPM2), and Protein Phosphatase 1 Regulatory Subunit 12C (PPP1R12C). In a recent study, Integrin Subunit Alpha 2b (ITGA2B), platelet and megakaryocytes transmembrane glycoprotein, involved in platelet aggregation [71] and in thrombasthenia, was identified as NSCLC platelet RNA marker in a test and an independent validation cohort [72]. TEPs RNA analysis may be complementary to currently in use non-invasive screenings to enhance the early stage cancer detection, characterization and monitoring in order to make therapy more efficient.

\section{Other oncogenic drivers in lung cancer}

Other molecular aberrations, named oncogene-addicted, drive both cancer growth and persistence, dramatically changing NSCLC therapy approach. EGFR mutations, ALK translocations, and ROS1 rearrangement require to be identified in cancerous biopsy in order to establish the proper therapeutic scheme. For example, $B R A F$ V600 mutations identification lead the therapy choice to effective trametinib/dabrafenib combination, while ROS1 fusions are efficiently treated with crizotinib. Advanced NSCLC can be treated with several EGFR 
tyrosine kinase inhibitors (TKIs) (erlotinib, afatinib, osimertinib and gefitinib) and ALKi (ceritinib, alectinib and crizotinib) approved both in US and Europe [73]. There are other evidence showing that BRAF, MET, ROS1, AKT, HER2, PIK3CA, RET, KRAS, and DDR2 alteration may lead oncogenic transformation in NSCLC [7]. Recently, BRAF and ROS1 targeted therapies were approved for NSCLC in advanced stages [8, 74]. Moreover, novel EGFR and ALK TKIs are being used in therapy since they are effective on refractory tumor resistant to previous generations ones [75]. EGFR mutations were discovered in 2004 in NSCLC, when the results of clinical studies with EGFR TKIs resulted comparable to chemotherapy [76, 77]. Second and third generation EGFRTKIs drugs have been developed and used, respectively afatinib and osimertinib in patients who developed the EGFR-T790M mutation that confers resistance to erlotinib and gefitinib [78]. In 2007 an aberrant fusion of EML4 and ALK was discovered in NSCLC patients [79]. Crizotinib, an oral TKI effective against ALK, ROS1 and MET, represented the first therapeutic approach used against this alteration [80]. This drug presented significant advantages compared to older drugs frequently used as first and the second line therapy, so it became the first choice in untreated NSCLC patients showing this alteration. ROS1 gene mutations were discovered in 2007 in NSCLC with a frequency of 1-2\% [81]. Several mutations conferring resistance were reported (S1986Y/F, L1951R, D2033N, L2026M), but the most frequent is G2032R mutation responsible for steric hindrance preventing the drug to bind correctly to its binding site and exploiting its activity [82]. Ceritinib showed similar activity on $L 2026 \mathrm{M}$ resistance mutation compared to brigatinib resistance mutation, but not on D2033N, L1951R and G2032R [83]. Only cabozantinib is active against G2032R mutation but it has severe side effects and toxicity limiting its use [84]. Targeted therapy is a strongly and rapidly growing field, many new alternatives are expected in the upcoming years.

\section{Conclusion and perspectives}

In this report, we briefly highlighted how liquid lung biopsy can be a promising valid tool for the monitoring and early diagnosis of lung cancer, providing important genomic information viable for individualized treatment strategies. We showed the various biomarkers like CTCs, TEPs, ctDNA and exosomes and the relative technologies today in use are important to obtain crucial information about somatic mutations and gene alterations leading to tumor progression and development. Moreover, miRNAs profiling could be useful to couple with a standard radiological screening test in order to improve the diagnosis. The analytes used for liquid biopsy have their own advantages and disadvantages that must be accounted when choosing a specific marker answering to a specific clinical question. CTCs are relatively rare in early cancers, but they provide a particularly powerful approach to detect a variety of cancer-specific abnormalities present in advanced cancers, such as androgen receptor splice variants. In personalized medicine era, liquid NSCLC biopsy represents a valid and alternative non-invasive method compared to tissue biopsy, complementary to other techniques currently used for diagnosis and monitoring. Moreover, tissues genomic profile provides a tumor picture limited to a single time point. Liquid biopsy, unlike usual techniques, embraces the complex heterogeneity, especially in time, and the deep biological basis of tumors. Although the use of different highthroughput analytical platforms may result in reproducibility problem, the present manuscript underlines the requirement of improved standardization and methods analytical validation for liquid biopsy. However, liquid lung biopsy methods can become more standardized and offer maximum sensitivity using commercially available platforms and tests. Advances in technology, particularly the introduction of NGS techniques, could help the liquid biopsy even more viable. Each biomarker (ctDNA, CTCs, exosome, and TEPs) has its own characteristics but all of them provide some crucial information about all kind of cancer genomic alterations like point mutations, translocations, amplifications and even epigenetic alterations. (Table 1).

Circulating tumor DNA assays detecting sensitizing mutations and resistance to EGFR already entered in the clinical practice and the detection of resistance mutations for rearrangements of tyrosine kinase of the ALK receptor will certainly follow in the routine use soon enough. Liquid biopsy offers genomic cancer cell profile through the non-invasive and cheap blood sampling or other low-cost body fluids, thus representing one of the most interesting and rapidly improving fields in lung cancer. 
Table 1. Different characteristics of biomarkers in liquid biopsy

\begin{tabular}{|c|c|c|}
\hline Biomarker & Technique & Application \\
\hline CTC & $\begin{array}{l}\text { CTC CellSearch }{ }^{\mathrm{TM}} \text { (Veridex LLC) utilizes } \\
\text { ferroparticles and antibodies directed to epithelial } \\
\text { targets (EpCAM) }\end{array}$ & $\begin{array}{l}\text { Provide RNAs, DNA and proteins for cancer } \\
\text { diagnosis and profiling; give information about } \\
\text { progression and metastasis }\end{array}$ \\
\hline ctDNA and cfDNA & $\begin{array}{l}\text { PCR, dPCR, ddPCR, gripper-based peptide } \\
\text { acid-based PCR test. PNA Taqman dosage, } \\
\text { microspheres, BEAMing, NGS }\end{array}$ & $\begin{array}{l}\text { High sensitivity (one of the highest) for detection of } \\
\text { early lung cancer; information about the presence } \\
\text { of mutated genes correlates to poor prognosis }\end{array}$ \\
\hline Exosome & $\begin{array}{l}\text { Isolation by physical or biological properties; } \\
\text { MACS; immune-mediated isolation; sucrose } \\
\text { gradient method; ultracentrifugation; after isolation, } \\
\text { PCR used to separate the RNA and proteins }\end{array}$ & $\begin{array}{l}\text { Important in early diagnosis and prognosis; } \\
\text { information about tumor's biologic profile, growth } \\
\text { rate, metastatic capacity and drug resistance; } \\
\text { potential vehicle for therapies }\end{array}$ \\
\hline TEP & $\begin{array}{l}\text { Extraction of tumor biomolecules and nucleic acids } \\
\text { (RNAs) }\end{array}$ & $\begin{array}{l}\text { Give large amount of genetic material (RNA } \\
\text { and DNA); diagnosis of lung cancer; treatment } \\
\text { monitoring }\end{array}$ \\
\hline
\end{tabular}

\section{Abbreviations}

AKT: protein kinase B

ALK: anaplastic lymphoma kinase

BEAMing: beads, emulsion, amplification and magnetics

BRAF: B-Raf proto-oncogene

cfDNA: cell-free DNA

CTCs: circulating cancer cells

ctDNA: circulating tumor DNA

ddPCR: digital droplet-polymerase chain reactio

DDR2: discoidin domainreceptor tyrosine kinase 2

dPCR: digital PCR

EGFR: epidermal growth factor receptor

EML4: echinoderm microtubule-associated protein-like 4

EMT: epithelial-mesenchymal transition

EpCAM: epithelial cell adhesion molecule

HER2: human epidermal growth factor receptor 2

KRAS: K-Ras protein coding gene

LDCT: low dose computed tomography

MET: hepatocyte growth factorreceptor coding gene

NGS: next generation sequencing

NLST: National Lung Screening Trial

NSCLC: non-small cell lung cancer

PCR: polymerase chain reaction

PIK3CA: phosphatidylinositol-4,5-bisphosphate 3-kinase catalytic subunit alpha

PNA: peptide nucleic acid

qPCR: quantitative polymerase chain reaction

RET: proto-oncogene tyrosine-protein kinase receptor coding gene

ROS1: ROS proto-oncogene 1

RT-PCR: real time polymerase chain reaction

SCC: squamous cell carcinoma

TEPs: tumor-educated platelets 
TKIs: tyrosine kinase inhibitors

VEGF: vascular endothelial growth factor

\section{Declarations}

\section{Author contributions}

AMC and MS drafted the article. AMC, AL, AG, MR, AO and MB contributed in formatting the manuscript. MC and $\mathrm{MB}$ revised the final version.

\section{Conflicts of interest}

The authors declare that they have no conflicts of interest.

\section{Ethical approval}

Not applicable.

\section{Consent to participate}

Not applicable.

\section{Consent to publication}

Not applicable.

\section{Availability of data and materials}

Not applicable.

\section{Funding}

Not applicable.

\section{Copyright}

(C) The Author(s) 2020.

\section{References}

1. National Lung Screening Trial Research Team; Aberle DR, Berg CD, Black WC, Church TR, Fagerstrom RM, Galen B, et al. The National Lung Screening Trial: overview and study design. Radiology. 2011;258:243-53.

2. Govindan R, Page N, Morgensztern D, Read W, Tierney R, Vlahiotis A, et al. Changing epidemiology of smallcell lung cancer in the United States over the last 30 years: analysis of the surveillance, epidemiologic, and end results database. J Clin Oncol. 2006;24:4539-44.

3. Hirsch FR, Scagliotti GV, Mulshine JL, Kwon R, Curran WJ Jr, Wu YL, et al. Lung cancer: current therapies and new targeted treatments. Lancet. 2017;389:299-311.

4. Minna JD, Roth JA, Gazdar AF. Focus on lung cancer. Cancer Cell. 2002;1:49-52.

5. Cersosimo RJ. Lung cancer: a review. Am J Health Syst Pharm. 2002;59:611-42.

6. Canale M, Pasini L, Bronte G, Delmonte A, Cravero P, Crinò L, et al. Role of liquid biopsy in oncogeneaddicted non-small cell lung cancer. Transl Lung Cancer Res. 2019;8 Suppl 3:S265-79.

7. Schulze AB, Evers G, Kerkhoff A, Mohr M, Schliemann C, Berdel WE, et al. Future options of moleculartargeted therapy in small cell lung cancer. Cancers (Basel). 2019;11:690.

8. Shaw AT, Ou SH, Bang YJ, Camidge DR, Solomon BJ, Salgia R, et al. Crizotinib in ROS1-rearranged nonsmall-cell lung cancer. N Engl J Med. 2014;371:1963-71.

9. Bironzo P, Di Maio M. A review of guidelines for lung cancer. J Thorac Dis. 2018;10 Suppl 3:S1556-63. 
10. National Lung Screening Trial Research Team; Aberle DR, Adams AM, Berg CD, Black WC, Clapp JD, Fagerstrom RM, et al. Reduced lung-cancer mortality with low-dose computed tomographic screening. N Engl J Med. 2011;365:95-409.

11. Patz EF Jr, Pinsky P, Gatsonis C, Sicks JD, Kramer BS, Tammemägi MC, et al; NLST Overdiagnosis Manuscript Writing Team. Overdiagnosis in low-dose computed tomography screening for lung cancer. JAMA Intern Med. 2014;174:269-74.

12. Paci E, Puliti D, Lopes Pegna A, Carrozzi L, Picozzi G, Falaschi F, et al; the ITALUNG Working Group. Mortality, survival and incidence rates in the ITALUNG randomised lung cancer screening trial. Thorax. 2017;72:825-31.

13. Infante M, Sestini S, Galeone C, Marchianò A, Lutman FR, Angeli E, et al. Lung cancer screening with lowdose spiral computed tomography: evidence from a pooled analysis of two Italian randomized trials. Eur J Cancer Prev. 2017;26:324-9.

14. Santarpia M, Karachaliou N, González-Cao M, Altavilla G, Giovannetti E, Rosell R. Feasibility of cell-free circulating tumor DNA testing for lung cancer. Biomark Med. 2016;10:417-30.

15. Perakis S, Speicher MR. Emerging concepts in liquid biopsies. BMC Med. 2017;15:75.

16. Siravegna G, Marsoni S, Siena S, Bardelli A. Integrating liquid biopsies into the management of cancer. Nat Rev Clin Oncol. 2017;14:531-48.

17. Sozzi G, Conte D, Leon M, Ciricione R, Roz L, Ratcliffe C, et al. Quantification of free circulating DNA as a diagnostic marker in lung cancer. J Clin Oncol. 2003;21:3902-8.

18. Crowley E, Di Nicolantonio F, Loupakis F, Bardelli A. Liquid biopsy: monitoring cancer-genetics in the blood. Nat Rev Clin Oncol. 2013;10:472-84.

19. Tie J, Wang Y, Tomasetti C, Li L, Springer S, Kinde I, et al. Circulating tumor DNA analysis detects minimal residual disease and predicts recurrence in patients with stage II colon cancer. Sci Transl Med. 2016;8:346ra92.

20. Hong Y, Fang F, Zhang Q. Circulating tumor cell clusters: what we know and what we expect (Review). Int J Oncol. 2016;49:2206-16.

21. Allard WJ, Matera J, Miller MC, Repollet M, Connelly MC, Rao C, et al. Tumor cells circulate in the peripheral blood of all major carcinomas but not in healthy subjects or patients with nonmalignant diseases. Clin Cancer Res. 2004;10:6897-904.

22. Cristofanilli M, Budd GT, Ellis MJ, Stopeck A, Matera J, Miller MC, et al. Circulating tumor cells, disease progression, and survival in metastatic breast cancer. N Engl J Med. 2004;351:781-91.

23. De Craene B, Berx G. Regulatory networks defining EMT during cancer initiation and progression. Nat Rev Cancer. 2013;13:97-110.

24. Nagrath S, Sequist LV, Maheswaran S, Bell DW, Irimia D, Ulkus L, et al. Isolation of rare circulating tumour cells in cancer patients by microchip technology. Nature. 2007;450:1235-9.

25. Raimondi C, Nicolazzo C, Gradilone A. Circulating tumor cells isolation: the "post-EpCAM era". Chin J Cancer Res. 2015;27:461-70.

26. Desitter I, Guerrouahen BS, Benali-Furet N, Wechsler J, Jänne PA, Kuang Y, et al. A new device for rapid isolation by size and characterization of rare circulating tumor cells. Anticancer Res. 2011;31:427-41.

27. Babayan A, Alawi M, Gormley M, Müller V, Wikman H, McMullin RP, et al. Comparative study of whole genome amplification and next generation sequencing performance of single cancer cells. Oncotarget. 2016;8:56066-8.

28. Hanssen A, Wagner J, Gorges TM, Taenzer A, Uzunoglu FG, Driemel G, et al. Characterization of different CTC subpopulations in non-small cell lung cancer. Sci Rep. 2016;6:28010.

29. Maheswaran S, Sequist LV, Nagrath S, Ulkus L, Brannigan B, Collura CV, et al. Detection of mutations in EGFR in circulating lung cancer cells. N Engl J Med. 2008;359:66-77. 
30. Mayo C, Ortega FG, Giménez-Capitán A, Molina-Vila MA, Serrano MJ, Viteri S, et al. CK-coated magneticbased beads as a tool to isolate circulating tumor cells (CTCs) in human tumors. Transl Lung Cancer Res. 2013;2:65-71.

31. Fiorelli A, Accardo M, Carelli E, Angioletti D, Santini M, Di Domenico M. Circulating tumor cells in diagnosing lung cancer: clinical and morphologic analysis. Ann Thorac Surg. 2015;99:1899-905.

32. Ilie M, Hofman V, Long-Mira E, Selva E, Vignaud JM, Padovani B, et al. "Sentinel” circulating tumor cells allow early diagnosis of lung cancer in patients with chronic obstructive pulmonary disease. PLoS One. 2014;9:e111597.

33. Yu Y, Chen Z, Dong J, Wei P, Hu R, Zhou C, et al. Folate receptor-positive circulating tumor cells as a novel diagnostic biomarker in non-small cell lung cancer. Transl Oncol. 2013;6:697-702.

34. Xu Y, Liu B, Ding F, Zhou X, Tu P, Yu B, et al. Circulating tumor cell detection: a direct comparison between negative and unbiased enrichment in lung cancer. Oncol Lett. 2017;13:4882-6.

35. Lin M, Chen JF, Lu YT, Zhang Y, Song J, Hou S, et al. Nanostructure embedded microchips for detection, isolation, and characterization of circulating tumor cells. Acc Chem Res. 2014;47:2941-50.

36. Ming Y, Li Y, Xing H, Luo M, Li Z, Chen J, et al. Circulating tumor cells: from theory to nanotechnologybased detection. Front Pharmacol. 2017;8:35.

37. Lim M, Kim CJ, Sunkara V, Kim MH, Cho YK. Liquid biopsy in lung cancer: clinical applications of circulating biomarkers (CTCs and ctDNA). Micromachines (Basel). 2018;9:100.

38. Jahr S, Hentze H, Englisch S, Hardt D, Fackelmayer FO, Hesch RD, et al. DNA fragments in the blood plasma of cancer patients: quantitations and evidence for their origin from apoptotic and necrotic cells. Cancer Res. 2001;61:1659-65.

39. Karachaliou N, Gonzalez-Cao M, Sosa A, Berenguer J, Bracht JWP, Ito M, et al. The combination of checkpoint immunotherapy and targeted therapy in cancer. Ann Transl Med. 2017;5:388.

40. Mayo-de-Las-Casas C, Garzón Ibáñez M, Jordana-Ariza N, García-Peláez B, Balada-Bel A, Villatoro S, et al. An update on liquid biopsy analysis for diagnostic and monitoring applications in non-small cell lung cancer. Expert Rev Mol Diagn. 2018;18:35-45.

41. Forshew T, Murtaza M, Parkinson C, Gale D, Tsui DW, Kaper F, et al. Noninvasive identification and monitoring of cancer mutations by targeted deep sequencing of plasma DNA. Sci Transl Med. 2012;4:136ra68.

42. Gautschi O, Bigosch C, Huegli B, Jermann M, Marx A, Chassé E, et al. Circulating deoxyribonucleic Acid as prognostic marker in non-small-cell lung cancer patients undergoing chemotherapy. J Clin Oncol. 2004;22:4157-64.

43. Newman AM, Bratman SV, To J, Wynne JF, Eclov NC, Modlin LA, et al. An ultrasensitive method for quantitating circulating tumor DNA with broad patient coverage. Nat Med. 2014;20:548-54.

44. Zheng H, Zhan Y, Liu S, Lu J, Luo J, Feng J, et al. The roles of tumor-derived exosomes in non-small cell lung cancer and their clinical implications. J Exp Clin Cancer Res. 2018;37:226.

45. Valadi H, Ekström K, Bossios A, Sjöstrand M, Lee JJ, Lötvall JO. Exosome-mediated transfer of mRNAs and microRNAs is a novel mechanism of genetic exchange between cells. Nat Cell Biol. 2007;9:654-9.

46. Mathivanan S, Ji H, Simpson RJ. Exosomes: extracellular organelles important in intercellular communication. J Proteomics. 2010;73:1907-20.

47. Rani S, O'Brien K, Kelleher FC, Corcoran C, Germano S, Radomski MW, et al. Isolation of exosomes for subsequent mRNA, MicroRNA, and protein profiling. Methods Mol Biol. 2011;784:181-95.

48. Abdouh M, Hamam D, Gao ZH, Arena V, Arena M, Arena GO. Exosomes isolated from cancer patients' sera transfer malignant traits and confer the same phenotype of primary tumors to oncosuppressor-mutated cells. J Exp Clin Cancer Res. 2017;36:113. 
49. Reclusa P, Taverna S, Pucci M, Durendez E, Calabuig S, Manca P, et al. Exosomes as diagnostic and predictive biomarkers in lung cancer. J Thorac Dis. 2017;9 Suppl 13:S1373-82.

50. Wu H, Esteve E, Tremaroli V, Khan MT, Caesar R, Mannerås-Holm L, et al. Metformin alters the gut microbiome of individuals with treatment-naive type 2 diabetes, contributing to the therapeutic effects of the drug. Nat Med. 2017;23:850-8.

51. Cazzoli R, Buttitta F, Di Nicola M, Malatesta S, Marchetti A, Rom WN, et al. microRNAs derived from circulating exosomes as noninvasive biomarkers for screening and diagnosing lung cancer. J Thorac Oncol. 2013;8:1156-62.

52. Jin X, Chen Y, Chen H, Fei S, Chen D, Cai X, et al. Evaluation of tumor-derived exosomal miRNA as potential diagnostic biomarkers for early-stage non-small cell lung cancer using next-generation sequencing. Clin Cancer Res. 2017;23:5311-9.

53. Zomer A, Maynard C, Verweij FJ, Kamermans A, Schäfer R, Beerling E, et al. In vivo imaging reveals extracellular vesicle-mediated phenocopying of metastatic behavior. Cell. 2015;161:1046-57.

54. Yamashita T, Honda M, Nakamoto Y, Baba M, Nio K, Hara Y, et al. Discrete nature of EpCAM+ and CD90+ cancer stem cells in human hepatocellular carcinoma. Hepatology. 2013;57:1484-97.

55. Labelle M, Begum S, Hynes RO. Platelets guide the formation of early metastatic niches. Proc Natl Acad Sci U S A. 2014;111:E3053-61.

56. Janowska-Wieczorek A, Wysoczynski M, Kijowski J, Marquez-Curtis L, Machalinski B, Ratajczak J, et al. Microvesicles derived from activated platelets induce metastasis and angiogenesis in lung cancer. Int J Cancer. 2005;113:752-60.

57. Haemmerle M, Taylor ML, Gutschner T, Pradeep S, Cho MS, Sheng J, et al. Platelets reduce anoikis and promote metastasis by activating YAP1 signaling. Nat Commun. 2017;8:310.

58. Labelle M, Begum S, Hynes RO. Direct signaling between platelets and cancer cells induces an epithelialmesenchymal-like transition and promotes metastasis. Cancer Cell. 2011;20:576-90.

59. Klement GL, Yip TT, Cassiola F, Kikuchi L, Cervi D, Podust V, et al. Platelets actively sequester angiogenesis regulators. Blood. 2009;113:2835-42.

60. McAllister SS, Weinberg RA. The tumour-induced systemic environment as a critical regulator of cancer progression and metastasis. Nat Cell Biol. 2014;16:717-27.

61. Jiang X, Wong KHK, Khankhel AH, Zeinali M, Reategui E, Phillips MJ, et al. Microfluidic isolation of plateletcovered circulating tumor cells. Lab Chip. 2017;17:3498-503.

62. Alhasan AA, Izuogu OG, Al-Balool HH, Steyn JS, Evans A, Colzani M, et al. Circular RNA enrichment in platelets is a signature of transcriptome degradation. Blood. 2016;127:e1-11.

63. Rondina MT, Schwertz H, Harris ES, Kraemer BF, Campbell RA, Mackman N, et al. The septic milieu triggers expression of spliced tissue factor mRNA in human platelets. J Thromb Haemost. 2011;9:748-58.

64. Stone RL, Nick AM, McNeish IA, Balkwill F, Han HD, Bottsford-Miller J, et al. Paraneoplastic thrombocytosis in ovarian cancer. N Engl J Med. 2012;366:610-8.

65. Pucci F, Rickelt S, Newton AP, Garris C, Nunes E, Evavold C, et al. PF4 promotes platelet production and lung cancer growth. Cell Rep. 2016;17:1764-72.

66. Calverley DC, Phang TL, Choudhury QG, Gao B, Oton AB, Weyant MJ, et al. Significant downregulation of platelet gene expression in metastatic lung cancer. Clin Transl Sci. 2010;3:227-32.

67. Best MG, Sol N, Kooi I, Tannous J, Westerman BA, Rustenburg F, et al. RNA-Seq of tumor-educated platelets enables blood-based pan-cancer, multiclass, and molecular pathway cancer diagnostics. Cancer Cell. 2015;28:666-76.

68. Best MG, Sol N, In 't Veld SGJG, Vancura A, Muller M, Niemeijer AN, et al. Swarm intelligence-enhanced detection of non-small-cell lung cancer using tumor-educated platelets. Cancer Cell. 2017;32:238-5. 
69. Nilsson RJ, Karachaliou N, Berenguer J, Gimenez-Capitan A, Schellen P, Teixido C, et al. Rearranged EML4-ALK fusion transcripts sequester in circulating blood platelets and enable blood-based crizotinib response monitoring in non-small-cell lung cancer. Oncotarget. 2016;7:1066-75.

70. Sheng M, Dong Z, Xie Y. Identification of tumor-educated platelet biomarkers of non-small-cell lung cancer. Onco Targets Ther. 2018;11:8143-51.

71. Heidenreich R, Eisman R, Surrey S, Delgrosso K, Bennett JS, Schwartz E, et al. Organization of the gene for platelet glycoprotein IIb. Biochemistry. 1990;29:1232-44.

72. Xing S, Zeng T, Xue N, He Y, Lai YZ, Li HL, et al. Development and validation of tumor-educated blood platelets integrin alpha 2b (ITGA2B) RNA for diagnosis and prognosis of non-small-cell lung cancer through RNA-seq. Int J Biol Sci. 2019;15:1977-92.

73. Tsakonas G, Ekman S. Oncogene-addicted non-small cell lung cancer and immunotherapy. J Thorac Dis. 2018;10 Suppl 13:S1547-55.

74. Baik CS, Myall NJ, Wakelee HA. Targeting BRAF-mutant non-small cell lung cancer: from molecular profiling to rationally designed therapy. Oncologist. 2017;22:786-96.

75. Novello S, Mazières J, Oh IJ, de Castro J, Migliorino MR, Helland $\AA$, et al. Alectinib versus chemotherapy in crizotinib-pretreated anaplastic lymphoma kinase (ALK)-positive non-small-cell lung cancer: results from the phase III ALUR study. Ann Oncol. 2018;29:1409-16.

76. Rosell R, Carcereny E, Gervais R, Vergnenegre A, Massuti B, Felip E, et al; Spanish Lung Cancer Group in collaboration with Groupe Français de Pneumo-Cancérologie and Associazione Italiana Oncologia Toracica. Erlotinib versus standard chemotherapy as first-line treatment for European patients with advanced EGFR mutation-positive non-small-cell lung cancer (EURTAC): a multicentre, open-label, randomised phase 3 trial. Lancet Oncol. 2012;13:239-46.

77. Mok TS, Wu YL, Thongprasert S, Yang CH, Chu DT, Saijo N, et al. Gefitinib or carboplatin-paclitaxel in pulmonary adenocarcinoma. N Engl J Med. 2009;361:947-57.

78. Mok TS, Wu YL, Ahn MJ, Garassino MC, Kim HR, Ramalingam SS, et al; AURA3 Investigators. Osimertinib or platinum-pemetrexed in EGFR T790M-positive lung cancer. N Engl J Med. 2017;376:629-40.

79. Soda M, Choi YL, Enomoto M, Takada S, Yamashita Y, Ishikawa S, et al. Identification of the transforming EML4-ALK fusion gene in non-small-cell lung cancer. Nature. 2007;448:561-6.

80. Katayama R, Lovly CM, Shaw AT. Therapeutic targeting of anaplastic lymphoma kinase in lung cancer: a paradigm for precision cancer medicine. Clin Cancer Res. 2015;21:2227-35.

81. Bergethon K, Shaw AT, Ou SH, Katayama R, Lovly CM, McDonald NT, et al. ROS1 rearrangements define a unique molecular class of lung cancers. J Clin Oncol. 2012;30:863-70.

82. Awad MM, Katayama R, McTigue M, Liu W, Deng YL, Brooun A, et al. Acquired resistance to crizotinib from a mutation in CD74-ROS1. N Engl J Med. 2013;368:2395-401.

83. Gainor JF, Tseng D, Yoda S, Dagogo-Jack I, Friboulet L, Lin JJ, et al. Patterns of metastatic spread and mechanisms of resistance to crizotinib in ROS1-positive non-small-cell lung cancer. JCO Precis Oncol. 2017; [Epub ahead of print].

84. Drilon A, Rekhtman N, Arcila M, Wang L, Ni A, Albano M, et al. Cabozantinib in patients with advanced RET-rearranged non-small-cell lung cancer: an open-label, single-centre, phase 2, single-arm trial. Lancet Oncol. 2016;17:1653-60. 